\title{
Ingeniería de Software aplicada al método global de análisis estructural para el aprendizaje del Español, Tének e Inglés en educación básica
}

\section{Software Engineering applied to the global method of structural analysis for Spanish, Tenek and English learning in basic education}

IZAGUIRRE-CÁRDENAS, Nelly Rosina*†, GARCIA-CHI, Rosa Imelda, HERNANDEZ, María Antonieta, y EGUIA-ALVAREZ, Arturo

SEP, Tecnológico Nacional de México. Instituto Tecnológico de Ciudad Valles, Carretera al Ingenio Km 2. Col. Vista Hermosa, CP. 79010, Cd. Valles, SLP, México.

ID $1^{\mathrm{er}}$ Autor: Nelly Rosina, Izaguirre-Cárdenas / ORC ID 0000-0003-4707, CVU CONACYT ID: 997704

ID $1^{\mathrm{er}}$ Coautor: Rosa Imelda, García-Chi / ORC ID 0000-0001-8462-2859, CVU CONACYT ID: 998355

ID $2^{\text {do }}$ Coautor: María Antonieta, Hernández / ORC ID 0000-0002-5568-3924, CVU CONACYT ID: 998431

ID $3^{\text {er }}$ Coautor: Arturo, Eguía-Alvarez / ORC ID 0000-0003-3034-3066, CVU CONACYT ID: 997835

DOI: $10.35429 / J A D .2019 .9 .3 .20 .25$

Recibido 22 de Junio, 2019; Aceptado 30 de Septiembre, 2019

\section{Resumen}

El método global de análisis estructural se caracteriza porque desde el primer momento se le presentan al niño unidades de información con un significado completo. El método global consiste en aplicar a la enseñanza de la lectura y escritura el mismo proceso que se sigue en los niños para enseñarles a hablar. El niño tiene una memoria visual, reconoce palabras, oraciones y frases, con esto, establece relaciones entre palabras y descubre los elementos idénticos en la imagen de dos palabras diferentes. La palabra escrita es el dibujo de una imagen que evoca cada idea. El modelo de prototipos de la ingeniería de software al aplicar la técnica de análisis, determina los requisitos funcionales del método global y lo transforma en un producto de software para la enseñanza de los lenguajes español, tének e inglés en niños de primer grado de primaria de la región de Ciudad Valles, San Luis Potosí. La metodología de prototipos tiene las siguientes etapas: comunicación, plan rápido, modelado, diseño, construcción del prototipo y desarrollo. El uso de la tecnología aunado al método global de enseñanza, logrará en los niños el aprendizaje significativo y constructivo de su lengua materna (tének), el idioma español y un idioma extranjero.

Software, Multilingüe, Método estructural

\begin{abstract}
The global method of structural analysis is characterized in that from the first moment the information units with a complete meaning are presented to the child. The global method is to apply to the teaching of reading and writing the same process that is followed in children to teach them to speak. The child has a visual memory, recognizes words, sentences and phrases, with this, establishes relationships between words and discovers the identical elements in the image of two different words. The written word is the drawing of an image that evokes each idea. The prototype model of software engineering when applying the analysis technique, determines the functional requirements of the global method and transforms it into a software product for teaching Spanish, Tenek and English in first grade primary school children. the region of Ciudad Valles, San Luis Potosí. The prototype methodology has the following stages: communication, rapid plan, modeling, design, prototype construction and development. The use of technology combined with the global teaching method will achieve in children the meaningful and constructive learning of their mother tongue (tének), the Spanish language and a foreign language.
\end{abstract}

Software, Multilingual, Structural method

Citación: IZAGUIRRE-CÁRDENAS, Nelly Rosina, GARCIA-CHI, Rosa Imelda, HERNANDEZ, María Antonieta, y EGUIA-ALVAREZ, Arturo. Ingeniería de Software aplicada al método global de análisis estructural para el aprendizaje del Español, Tének e Inglés en educación básica. Revista de Arquitectura y Diseño. 2019, 3-9: 20-25

\footnotetext{
*Correspondencia al Autor (Correo Electrónico: nelly.izaguirre@tecvalles.mx)
}

$\dagger$ Investigador contribuyendo como primer autor. 


\section{Introducción}

En la actualidad, la ingeniería de software afronta retos fundamentales en la producción de software, por lo que los ingenieros de software deben adoptar un enfoque sistemático y organizado producir software de alta calidad. La ingeniería de software hoy en día se puede aplicar en diversas áreas en combinación con otros métodos y técnicas.

La Ingeniería de Software "Trata del establecimiento de los principios y métodos de la Ingeniería a fin de obtener software de modo rentable que sea fiable y trabaje en máquinas reales." (Sommerville, 2005). Para lograr interpretar la realidad en la creación de un software, la metodología de software permite utilizar una estructura para planificar y controlar su procedimiento, desarrollar software no es una tarea fácil por lo que las metodologías imponen un proceso disciplinado sobre el desarrollo del mismo con el fin de hacerlo más predecible y eficiente.

Con el paso del tiempo han surgido una gran variedad de métodos y procedimientos para la enseñanza de la lectura y escritura. Algunos de los métodos de enseñanza de la lectura-escritura más utilizados en las escuelas son el Método de proceso sintético, método de proceso combinado y métodos de proceso analítico.

El método analítico o global se caracteriza porque desde el primer momento se le presenta al niño las unidades con un significado completo. Los niños pueden reconocer frases y oraciones y en ellas las palabras. Espontáneamente establecen relaciones y reconocen los elementos idénticos en la imagen de dos palabras diferentes. De este modo, la palabra escrita es el dibujo de una imagen que evoca cada idea. (García, 2011)

El método global de lector-escritura, especialmente introducido por Ovidio Decroly, se ha investigado que los precursores de este método fueron Jacotot (1770-1840), el religioso fray José Virazloing (1750) y Federico Gedike. Este método data del siglo XVIII, aunque no fue hasta el siglo XIX cuando se organizó definitivamente.
En Bélgica el método global fue aplicado antes de 1904 en el instituto de enseñanza especial de Bruselas dirigido por el Dr. Ovidio Decroly. Este método es conocido también como método de oraciones completas o método Decroly. (Metodos de alfabetización , 2014).

Para el desarrollo de este proyecto se utilizó el Modelo de Prototipo, el cual considera el uso de una Metodología de diseño que desarrolla rápidamente nuevos diseños, los evalúa y prescinde del prototipo cuando el próximo diseño es desarrollado mediante un nuevo prototipo. (EcuRed, 2019)

Las etapas para la implementación del Modelo de prototipo son: Recolección y refinamiento de requisitos, Modelado (Diseño rápido), construcción del prototipo, Desarrollo (Evaluación del prototipo por el cliente), Refinamiento del prototipo y Producto de Ingeniería. (Modelo de construcción de prototipos, 2013)

La ingeniería de software aplicada en el método global de análisis estructural con el uso del modelo de prototipo facilitó el aprendizaje del español, Tének e Inglés en los niños de primer año de primaria lo que permitió que se ampliara su vocabulario en los distintos idiomas.

\section{Descripción del Método}

La ingeniería de software es la aplicación de un enfoque sistemático, disciplinado y cuantificable al desarrollo, operación y mantenimiento de software; es decir, la aplicación de la ingeniería al software (Pressman,1988).

Una metodología de desarrollo de software no es más que una serie de pasos que se realizan de forma rigurosa tal que su resultado a partir de unos requisitos nuevos o modificados sea un software nuevo o modificado.

Un producto de software es de calidad si cumple rigurosamente con todos y cada uno de sus requisitos. Es decir, calidad $=$ requisitos satisfechos. 
Existen dos tipos principales de metodologías, las Ligeras y las Pesadas. Las primeras son metodologías extremadamente prácticas que generalmente obvian gran parte de la documentación y están más preparadas para utilizarse en proyectos cuyos requisitos cambiarán constantemente durante todo el proceso.

Las segundas, son metodologías donde todo está mucho más controlado y se genera muchísima documentación antes de proceder a implementar el proyecto, con mucho mayor peso del análisis y el diseño sobre el proyecto. Estas últimas son más indicadas para proyectos grandes o cuyo rendimiento y nivel de calidad son críticos para el éxito de éste.

El ciclo de vida del software es el conjunto de etapas que sigue un proyecto de software desde su concepción hasta su finalización y cierre, inclusive los mantenimientos (es decir, cambios o ajustes que puedan producirse una vez está implementado, nuevas versiones, etc.). Estos enfoques son: Cascada, Incremental, Espiral y Prototipo.

El enfoque prototipo es iterativo y se basa en realizar pequeños prototipos finales de la aplicación de forma que sus funcionalidades se construyen encima de la versión anterior, hasta llegar al producto definitivo y su entrega al cliente. (Girona, 2019)

El software que se implementó en las Escuelas primarias "Emiliano Zapata" e "Ignacio Zaragoza" de Cd. Valles contribuyo al fortalecimiento del uso del método global aún y cuando en la segunda no se llevaba a cabo de manera mecánica como en la primera.

Los resultados han sido favorables y se está buscando un convenio para implementar de manera permanente este software y se creen espacios en las planeaciones de los profesores y con ello contribuir en el proceso de enseñanza aprendizaje de los niños de primer año de primaria que inician con el aprendizaje de la lecto-escritura jugando mediante el uso de un software basado en el método global.

\section{Metodología}

Durante el desarrollo del prototipo se llevaron a cabo las siguientes actividades:

\section{1.-Recolección de requisitos.}

En esta etapa para la obtención de información se consideraron como muestra las siguientes escuelas primarias:

\section{Muestra 1 "Esc. Primaria Emiliano Zapata”}

a) 3 maestros de primer grado

b) Población aproximada de 100 niños

c) Tipo de materiales utilizados en las aulas

d) Estrategias didácticas y complementarias.

e) Inventario de hardware y software

\section{Muestra 2 "Esc. Primaria Ignacio Zaragoza"}

a) 1 maestro de primer grado

b) Población aproximada de 12 niños

c) Tipo de materiales utilizados en las aulas

d) Estrategias didácticas y complementarias.

e) Inventario de hardware y software

La información que se obtuvo fue la siguiente:

Muestra 1

- Se cuenta con tres grupos de primer año de grado escolar.

- $\quad$ El método global lo implementan en los niños con materiales a base de copias en blanco y negro. Las estrategias didácticas son utilizadas con el método global de manera mecánica.

- $\quad$ Los materiales que son proporcionados para su análisis son: Planeaciones del maestro, material de refuerzo y guías de apoyo y libros de texto gratuitos.

Muestra 2

- Se cuenta con un grupo de niños en cual se imparte primer y segundo año de grado escolar.

- $\quad$ No se usa el método global.

- Los materiales que son proporcionados para su análisis son: Libros de texto gratuitos. 


\section{2.- Plan rápido}

Una vez analizadas las especificaciones del cliente (profesor) tomadas de la recolección de requisitos se desarrolló la primera etapa de diseño rápido del prototipo para realizar la primera entrega. El lenguaje de programación utilizado fue Java ya que permite la creación de un ambiente interactivo y didáctico gracias a su entorno de desarrollo gráfico Java Netbeans y a la amplia gama de tecnologías de desarrollo de aplicaciones.

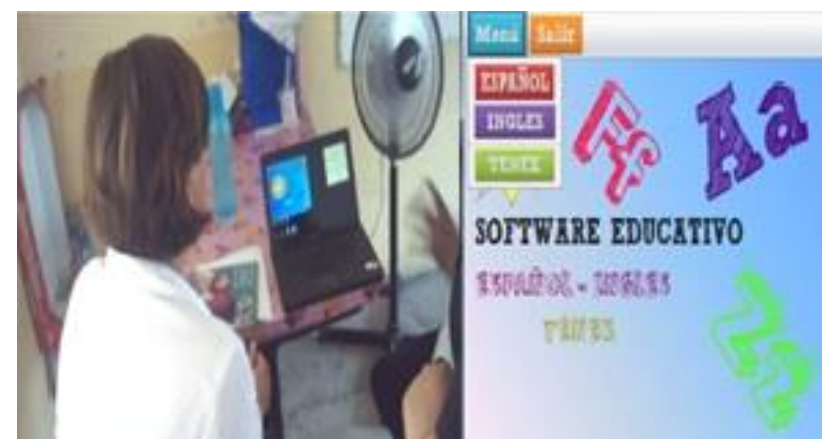

Figura 1 Diseño rápido e interfaz del software Fuente: Elaboración Propia

\section{3.- Modelado y diseño del Plan rápido}

En esta etapa de modelado y diseño de plan rápido el cliente realizo las siguientes observaciones durante la primera entrega.

a) Es importante que se muestre la pantalla completa del prototipo en la pantalla de la computadora ya que eso facilitara la manipulación del mismo por los niños.

b) Utilizar un estándar de estilos de fuentes para enfocar la atención del niño hacia el juego.

c) Se solicitó se utilice letra tipo alfa latina "a" para mejor comprensión de la visibilidad para los niños.

d) Que la visualización de las imágenes sean de mayor tamaño.

Una vez atendidas las observaciones se realizó una segunda entrega del prototipo.
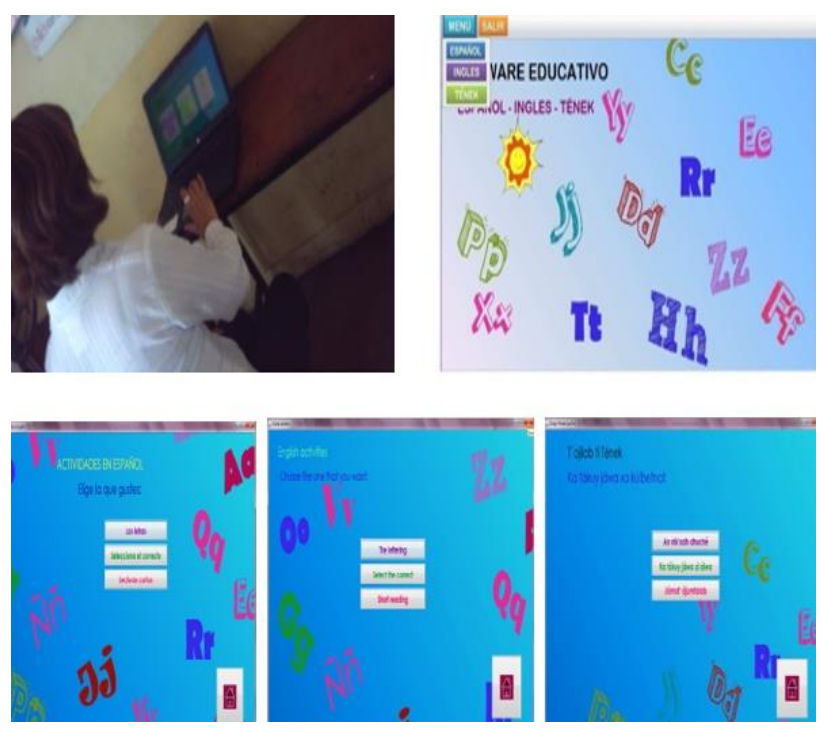

Figura 2 Interfaz del Software

Fuente: Elaboración Propia

4.- Desarrollo (Evaluación del prototipo por el cliente)

Los profesores probaron el software y realizaron observaciones de audio e imágenes, diseño de Pantallas secundarias por lo que se procedió a realizar las mejoras. Se diseñaron las actividades utilizando el método de análisis estructural, considerando los documentos de apoyo como material de refuerzo y guías de apoyo y libros de texto gratuitos proporcionados por las muestras 1 y 2 .

El prototipo cuenta con audio en cada uno de los botones de la pantalla principal y en cada una de sus actividades (Español, ingles, tenek). Se debe tomar en cuenta para el diseño del mismo, al presentar información textual, sonora $y$ visual de forma coordinada $e$ integrada, adaptar los contenidos y actividades a las características del alumno (cognitiva y de conocimientos previos) Lara, L. R. (2004).

Dicho lo anterior, se plasmaron en el prototipo experiencias de los docentes en relación al audio y la psicología del color para el diseño de las interfaces.

Las actividades agregadas son:

a) Lectura breve con dibujos relacionados

b) Imágenes atractivas para los niños con estilo de fuente alfa latina "a"

c) Ubicación de formas, fuentes y figuras que permiten que el niño centre su atención con el contexto de la oración presentada. 
d) Traducción al inglés y tenek de los materiales a utilizar

e) Vocabulario que incluye imágenes de objetos de la vida cotidiana utilizando colores y formas llamativas para los niños.

f) En el lenguaje tenek se agregó una sección de vocabulario de palabras o situaciones más comunes como son la escritura en tenek y su traducción al inglés y español.
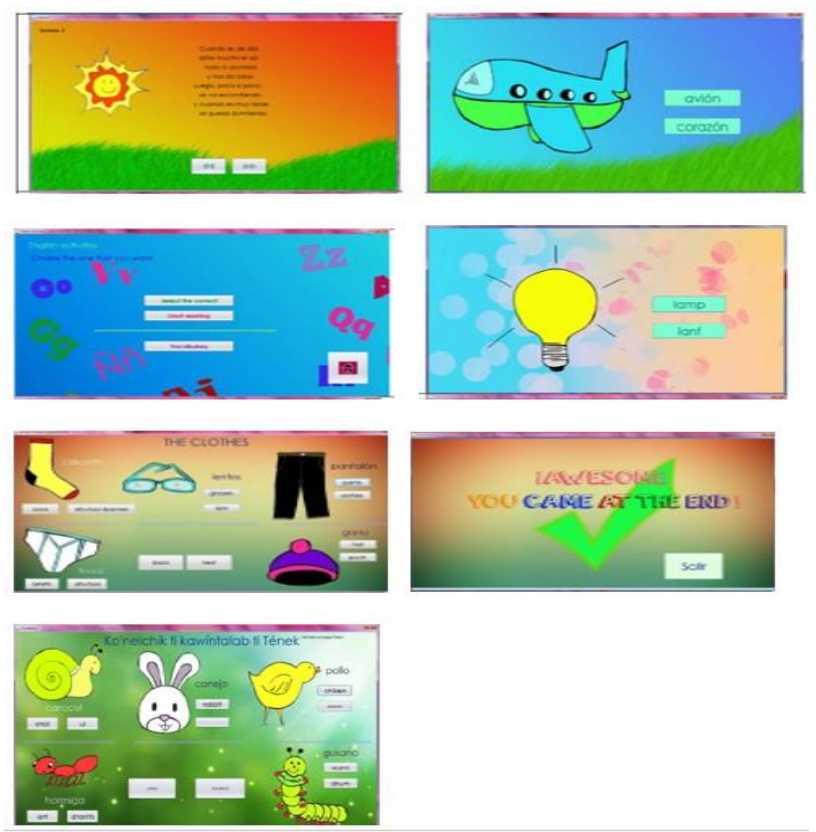

Figura 3 Producto de software final Fuente: Elaboración Propia

\section{5.- Refinamiento del prototipo}

En esta etapa se validó los requerimientos que se establecieron previamente en la etapa de recolección de requisitos, considerando las posibles modificaciones que puedan surgir por el cliente (profesor).

Se realiza una tercera entrega al cliente y se hacen las siguientes observaciones:

a) Que se considere trabajar por módulos las actividades del idioma español.

b) Agregar un audio a los botones que se encuentran en cada actividad.

c) Aumentar el tamaño del contenido de los textos por actividad.

Atendiendo las observaciones del cliente se realizan las siguientes modificaciones.

\section{1.- Para el idioma Español}

a) Se crean 6 módulos en que se incluye el abecedario de la A a la Z.

b) Se agregó en un apartado las lecturas cortas

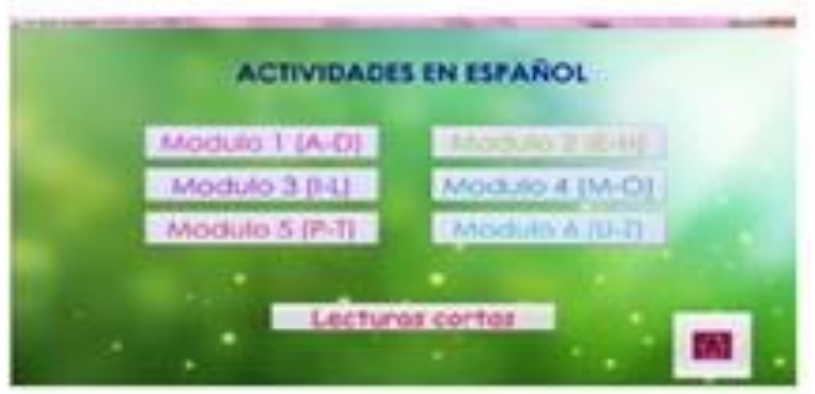

Figura 4 Apartado de Lecturas cortas

Fuente: Elaboración Propia

\section{2.- Para el idioma ingles}

a) Las actividades presentadas se mantuvieron

b) Se agregó en el apartado de vocabulario el audio correspondiente a cada imagen asociada a la actividad.

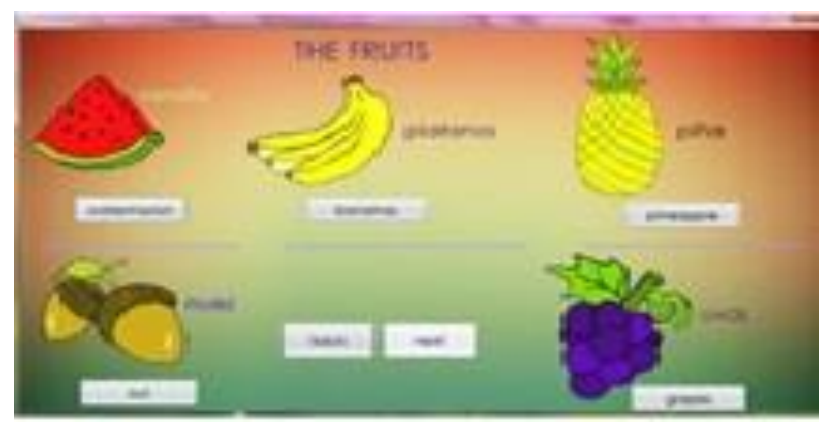

Figura 5 Apartado de vocabulario

Fuente: Elaboración Propia

3.- En las actividades sugeridas para el lenguaje Tenek no se realizaron observaciones por parte del cliente.

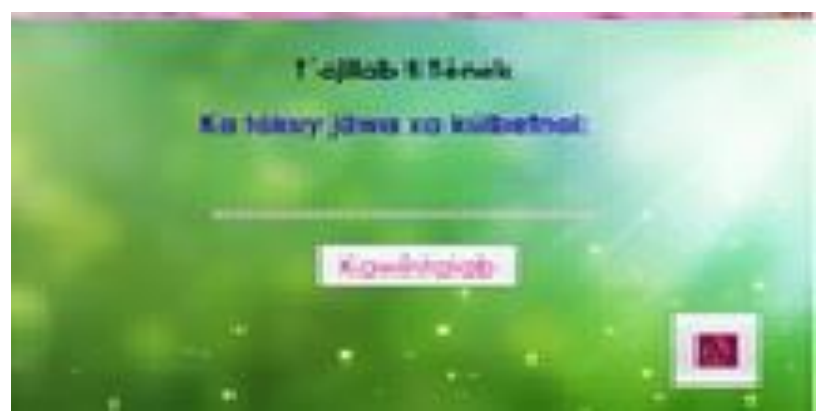

Figura 6 Interfaz en tének

Fuente: Elaboración Propia

IZAGUIRRE-CÁRDENAS, Nelly Rosina, GARCIA-CHI, Rosa Imelda, HERNANDEZ, María Antonieta, y EGUIA-ALVAREZ, Arturo. Ingeniería de Software aplicada al método global de análisis estructural para el aprendizaje del Español, Tének e Inglés en educación básica. Revista de Arquitectura y Diseño. 2019 


\section{Resultados}

Los resultados han sido favorables y se está buscando un convenio para implementar de manera permanente este software y se creen espacios en las planeaciones de los profesores y con ello contribuir en el proceso de enseñanza aprendizaje de los niños de primer año de primaria que inician con el aprendizaje de la lecto-escritura jugando mediante el uso de un software basado en el método global de análisis estructural.

\section{Conclusiones}

El software desarrollado fue utilizado como apoyo en las actividades docentes, brindo un aporte educativo tecnológico a los niños de la localidad, siendo la Escuela Primaria "Emiliano Zapata" y la Escuela Primaria "Ignacio Zaragoza" las que por medio de los niños de primer año utilizaron el software a través del juego, incrementando su vocabulario en español, inglés y tenek. La demanda de aprender por parte de los niños de la generación del "aquí y ahora" es mayor ya que tienen a su alcance cualquier tipo de información al momento. Como nativos digitales parte de sus habilidades están muy orientadas a la tecnológico por lo que hay un compromiso mayor con nuestra niñez al desarrollar nuevas propuestas para su aprendizaje.

\section{Referencias}

(2 de Agosto de 2019). Obtenido de https://www.ecured.cu/Modelo_de_prototipos\# Etapas

(12 de Agosto de 2019). Obtenido de http://ima.udg.edu/ sellares/EINF-

ES2/Present1011/MetodoPesadesDocumentacio .pdf

EcuRed. (2 de Septiembre de 2019). Obtenido de htps://www.ecured.cu/Modelo_de _prototipos

EcuRed. (10 de Agosto de 2019). Obtenido de https://www.ecured.cu/Modelo_de_prototipos\# Etapas
García, M. I. (Febrero de 2011). El metodo de lecto-escritura global. Innovación y Experiencias Educativas, 19. Obtenido de file:///C:/Users/nelly/Desktop/AgoDic2019/CICA/Material_MARIA\%20INMAC ULADA_ROSANO_MetodoLectoEscritura_R evisar.pdf

Girona, U. d. (12 de Agosto de 2019). Universidad de Girona. Obtenido de http://ima.udg.edu/ sellares/EINF-

ES2/Present1011/MetodoPesadesDocumentacio .pdf

Metodos de alfabetización . (13 de Diciembre de 2014). Obtenido de https://metodosalfabetizacion.wordpress.com/2 014/12/13/metodo-global/

Modelo de construcción de prototipos. (7 de Mayo de 2013). Obtenido de http://segundomodelo.blogspot.com/2013/05/m odelo-de-prototipos-este-modelo-no.html

Lara, L. R. (2004). Introducción a un modelo complejo de los softwares multimediales educativos. Revista de Educación a Distancia, (12).

Pressman, R. S., \& Troya, J. M. (1988). Ingeniería del software. 